iodine solvents, for similar difficulties were met, during this investigation, with amyl bromide and ethylene bromide. The first samples of these substances gave dark red iodine solutions, but after careful purification, pure violet solutions were obtained.

SAN Francisco, September 13, 1902.

[CONTRIBUTIONS FROM THE NEBRASKa EXPERIMENT STATION, No. I.SENT BY E. A. BURNETT.]

\title{
PRUSSIC ACID IN SORGHUM.
}

By HENRY B. SLADE.

Received October 3, Igoz.

INSTANCES of the fatal effects of green sorghum upon stock are frequently reported. The Nebraska Experiment Station records I 44 fatal cases in a single year. "At Imperial Io cattle out of a herd of 32 died suddenly. At Culbertson I I cattle died within an hour from eating cane. At Wauneta a stockman reports the loss of 7 head out of a small herd." 1 From Australia like cases are reported. ${ }^{2}$ In one instance $I 7$ animals in a single herd died from eating sorghum; in other instances cattle were allowed to feed upon the cane without loss. Berthelot and André in I886, in an article on "The Noxious Effects of Sorghum," ascribed the cause to excessive amounts of potassium nitrate. The late Mr. Williams, of the U. S. Department of Agriculture, also suggested saltpeter as the cause of the trouble. ${ }^{4}$ Determinations of the potassium nitrate in poisonous sorghum by Hiltner ${ }^{5}$ showed that the amount present was inadequate to the effect produced and the idea was presented that "the plant under certain conditions develops a highly poisonous chemical compound." In a paper before the Nebraska Section of the American Chemical Society ${ }^{8}$ the theory was put forward by the writer, in the fall of Igor, that such a poisonous compound might be produced by the action of an enzyme upon a glucoside formed in the plant through a process of abnormal growth. ${ }^{7}$ An examination of a sample of sorghum

1 Nebraska Experiment Station Bulletin No. 63 .

4 Quoted in Experiment Station Record, 13, 992.

3 Abstract in Biederinann's Centralblatt, 22, 470.

4 Farmers' Bulletin No. 50, p. I7.

5 Nebraska Experiment Station Bulletin No. 63 .

6 Nebraska Experiment Station, I5th Annual Report, p. 55 .

7 Dunstan and Henry have since confimed this view in the case of the Great Millet or Sorghum Vulgare of Egypt. Since the above article was contributed the attention of the 
from a lot which had proved fatal to cattle showed the presence of prussic acid. A further study appears to verify the view that the acid is split off from a compound through ferment action and a preliminary report of the results is now given.

The sample in question was received at the Station the fourth day after it had been cut. A portion was crushed by means of a sausage grinder, macerated with water for an hour and the filtered extract distilled into sodium hydroxide. On the addition of ferrous and ferric salts and acidulating with hydrochloric acid the characteristic blue color of the ferrocyanide of iron was obtained. The test was repeated with separate stalks with like results in every case. The prussic acid was also obtained as the nitroprusside and as silver cyanide. No prussic acid could be obtained from the water extracts of the roots but leaves and stalks both gave good tests, more marked in the stalks which appeared to yield the greater amount of the acid.

The same sample after drying in the laboratory for twelve days still yielded a decided test for prussic acid. Another sample of sorghum cut at the same time and cured in the field for six days and in the laboratory for twelve days likewise produced the acid on following the same procedure as in the other cases. The fact that the sorghum, if dried without crushing, still retains the power to produce prussic acid indicates the localization of the enzyme and acid-producing compound in separate cells of the plant. Quantitative estimations of the rield of prussic acid were made by macerating single stalks in a crushed condition for twelve hours in rubber-stoppered flasks. The acid formed was distilled into dilute sodium hydroxide and the amount of cyanide determined by titration with silver nitrate according to Liebig's method as directed by Fresenius. ${ }^{1}$ By this procedure o.or 3 per cent. of prussic acid was obtained in one case and o.or4 per cent. in writer has been called to the work of the two English investigators who have isolated a glucoside, dhurrin, which breaks up undet the action of an enzyme with the formation of prussic acid. (Chemical New's, June 2\%, rgo2.) From the brief account of the properties given, dhurrin does not seem to be identical with the prussic acid-forming glucoside of American cane. Dr. Samuel Avery, of the Nebraska Agricultural Experiment Station, in a private communication to the writer. states that under certain conditions the glucoside from American sorghum is decomposed by boiling hot water, which is not the case with dhurrin. It would be interesting to know whether the various glucosides yielding prussic acid form a chemical series similar to those of the saponin bodies worked out by Kobert.

I "Quantitative Analysis," p. 450 
another. On this basis a kilogram of sorghum would contain over twice the maximum medicinal dose for cattle, of the anhydrous acid and might prove fatal. Frohner ${ }^{1}$ places the fatal dose at 0.5 to I gram. At this rate 3.5 kilos of the cane would be extremely dangerous. A cow turned into the patch from which the above samples were taken developed the most marked symptoms of prussic acid poisoning after eating only a small amount of the cane. In the light of these results there would seem to be but little question that the poisoning of stock by sorghum is due to the prussic acid yielded by the plant.

The question still remains as to the formation of the prussic acid in the sorghum. Robiquet and Boutron-Charlard ${ }^{2}$ found prussic acid in oil of bitter almonds, and in 1837 Liebig and Wöhler ${ }^{3}$ discovered that the prussic acid was formed by the action of the emulsin upon the amygdalin in the almonds. Since that time prussic acid has been found in various plants and its formation has been generally ascribed to the action of emulsin upon some glucoside. In Igoo Dunstan and Henry discovered a new prussic acid-producing enzyme in the Egyptian vetch (Lotus arabicus) which they call lotase. Lotase splits up the glucoside, lotusin, with the production of prussic acid, a yellow coloringmatter, lotoflavin, and dextrose. Cattle in Northern Africa are oftentimes fatally poisoned by eating the vetch up to the time of the ripening of the seed. After that time the glucoside disappears and the plant becomes harmless. ${ }^{5}$

In the case of sorghum the poison seems to be formed by the action of an enzyme upon a glucoside. The fact that the dried plant still yielded prussic acid shows that it does not exist in that form in the plant. To determine whether the acid was formed by chemical or ferment action, extracts were made by digesting 20 grams of the sorghum pulp with $250 \mathrm{cc}$. of water at the temperature of the laboratory and also by pouring boiling hot water upon a like amount of pulp and boiling for five minutes. Both were allowed to macerate and then distilled as usual into

1 "Lehrbuch der Toxicologie," p. 860.

2 Quoted by Oppenheimer: "Ferments and Their Actions," English translation, p. 209.

3 Ann. Chem. Pharm., 21, $96 ; 22,17$.

4 Royal Society Proceedings, 67, $224 ; 68,374$.

b Thanks are due to Mr. V. K. Chesnut, of the Poisonous Plants Division of the U. $S$. Department of Agriculture, for this reference. 
sodium hydroxide. The former gave the usual marked test for the acid but the extract which had been boiled gave only the slightest trace of acid, the acidulated solution yielding only a faint green color after standing for some time. The formation of the prussic acid hence appeared due to a ferment action. However, as the compound producing the acid might be decomposed by simply boiling and the prussic acid formed thereby escape, extracts were also prepared with 95 per cent. alcohol, 2 per cent. sodium hydroxide, 0.4 per cent. hydrochloric acid, 0.2 per cent. sodium carbonate and 0.5 per cent. sodium chloride. In each of these tests 20 grams of the sorghum pulp and $250 \mathrm{cc}$. of the solvent were taken and a few drops of chloroform added to prevent bacterial action. The sorghum was introduced into the solvent so soon as it had been reduced to a pulp with a sausage grinder and the digestion continued for three clays in glassstoppered bottles at the room temperature; the liquid rapidly filtered through linen into a flask and distilled into sodium hydroxide. In the case of the alkaline extracts the liquid was rendered acid with dilute sulphuric acid before distilling. Neither the acid nor alkaline extracts showed a trace of prussic acid as was also the case with the alcoholic extract. On the other hand the sodium chloride extract gave a distinct test. If the formation of the acid were due to simple chemical decomposition through boiling, tests for the acid should have been obtained in every case. On the other hand the slight trace only of acid found in the boiled extract and the known hindering action of acids and alkalies as well as the favorable action of sodium chloride upon ferment action point to this as the source of the prussic acid. The behavior of the ferment in these respects would serve to identify it as emulsin but an extract with 40 per cent. alcohol yielded prussic acid while emulsin is sensitive to the presence of 8 per cent. alcohol. ${ }^{1}$ In studying the enzymes of sorghum the active preparations from the plant had no action upon amygdalin, from which the absence of emulsin was inferred. ${ }^{2}$ The active agent in this case may be a special form of emulsin such as that described by Jorrisen and Hairs ${ }^{3}$ or possibly a new enzyme. It does not appear to be ordinary emulsin. The glucase of sorghum acts upon

1 Effront: "Enzymes and Their Applications," English translation, 1, 270.

2 Nebraska Experiment Station, I5th Annual Report, p. $6 \mathrm{t}$.

3 Quoted by oppenheimer, p. 2 ro. 
glucosides and with amygdalin produces no prussic acid. The action of glucase, however, is not hindered, apparently, by hydrochloric acid.

From the above sample of poisonous sorghum, an enzyme preparation was obtained by precipitating the sorghum juice with 95 per cent. alcohol and again precipitating the alcoholic filtrate. The impure preparation thus obtained gave a decided blue color, which rapidly developed, with freshly-prepared tincture of guaiac and hydrogen peroxide but not after boiling the solution of the ferment. With various preparations from the sorghum this formed no prussic acid. The same preparations likewise gave negative tests for the acid after boiling with dilute mineral acids, neutralizing and testing with Fehling's solution. In every case where prussic acid was formed, the extract gave a rose-red color with strong hydrochloric acid in excess or with concentrated sulphuric acid. In the extracts where no prussic acid was formed no such reaction could be obtained. The most intense color was obtained from the water extracts of the stalks which was prepared by cutting off the stalks for four inches above the roots into small, quarter-inch pieces and macerating with water for an hour. This substance appears to be a coloring-matter formed together with the prussic acid by enzyme action. With alkalies the color produced by the acid disappears and returns on acidulating. With nitric acid the red color disappeared and on reducing the red hydrochloric acid solution of the substance with zinc dust no color appears on neutralizing.

This coloring-matter is precipitated by lead subacetate from which it may be again obtained by treating the precipitate suspended in water with hydrogen sulphide and treating the lead sulphide with hydrochloric acid. By filtering, neutralizing and extracting the residue with alcohol the compound may be isolated. The lead precipitate gives the characteristic brilliant rose-red with hydrochloric and sulphuric acids.

Thus far the suspected glucoside of American cane has not been isolated and the evidence for its existence rests upon the formation of prussic acid and a coloring-matter under the conditions described together with the general experience of the formation of prussic acid in plants. The evidence thus far at hand points to ferment action as the cause. 